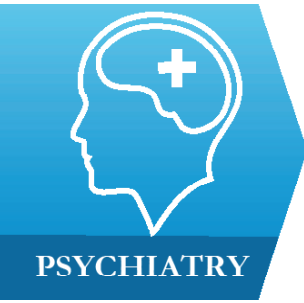

1) Minimally Invasive Surgery Research Center, Iran University of Medical Sciences, Tehran, Iran; Pediatric Growth and Development Research Center, Institute of Endocrinology and Metabolism, Iran University of Medical Sciences, Tehran, Iran

2) Minimally Invasive Surgery Research Center, Iran University of Medical Sciences, Tehran, Iran

3) Mental Health Research Center, Faculty of Medicine, Iran University of Medical Sciences, Tehran, Iran

4) School of Behavioral Sciences and Mental Health, Iran University of Medical Sciences, Tehran, Iran

5) Department of Biostatistics, School of Public Health, Iran University of Medical Sciences, Tehran, Iran

\title{
Risk factors for attention-deficit/hyperactivity disorder: a case-control study in 5 to 12 years old children
} Fahimeh Soheilipour ${ }^{1}$, Sareh Shiri ${ }^{2}$, Hamid Reza Ahmadkhaniha
Ebrahim Abdollahi

\begin{abstract}
Background and aims. Attention deficit/hyperactivity disorder (ADHD) is a common neurodevelopmental disorder known by a pattern of diminished sustained attention and increased impulsivity or hyperactivity. This study aimed to evaluate the risk factors associated with ADHD.

Methods. This case-control study included 297 ADHD children aged 5-12 years admitted to Tehran Institute of Psychiatry, Iran (2012-2013). They were compared with 297 non-ADHD (as controls matched to cases 1:1) who were of the same age ( \pm 1 years) selected from outpatients in general pediatric medical centers in Tehran. ADHD Rating Scale IV (ADHD-RS-IV)-Home Version was used to confirm ADHD. Data were analyzed using conditional binary logistic regression.

Results. Mean \pm SD age were $8.18 \pm 3.11$ and $8.11 \pm 2.9$ years in the case and control groups, respectively $(\mathrm{P}=0.61)$. Mean $\pm \mathrm{SD}$ birth weight $(\mathrm{BW})$ was higher in $\mathrm{ADHD}$ patients compared with the controls ( $3245.09 \pm 0.66$ vs $3026.56 \pm 0.45 \mathrm{gr}, \mathrm{P}=0.045)$. The results showed that odds of ADHD in children with high BW $(>3500 \mathrm{~g})$ was 3.36 (1.96-5.78) times the odds of ADHD in normal BW children (2500-3500g) controlling for other risk factors. ADHD risk in low BW children $(<2500 \mathrm{~g})$ was not statistically different compared with normal BW children [OR:1.74 (0.7-3.7)]. Experience of neonatal disease, fewer offspring, lower level of mothers' education, and preterm delivery were also risk factors for higher odds of ADHD.
\end{abstract}

Conclusion. Based on our sample, preterm birth, neonatal disease, high BW, lower level of mother's education, and fewer offspring were ADHD risk factors.

Keywords: attention deficit disorder with hyperactivity, risk factor, birth weight, logistic models

\section{Background and aims}

Attention-deficit/hyperactivity disorder (ADHD) as a common neurodevelopmental disorder [1] is known by a pattern of diminished sustained attention and increased impulsivity or hyperactivity [2-4]. In addition, there are some disturbances of neuropsychological functions [5] and some accessory symptoms including disorganization, emotional control, hot temper, and emotional lability [6].The worldwide prevalence of ADHD is reported to be about 5\% in childhood [7]. According to Conners scale, Tehran - the capital of Iran - had the highest prevalence of ADHD
$(19.9 \%)$ and Sanandaj province $(5.5 \%)$ had the lowest prevalence of ADHD in Iran [8]. ADHD risk factors detection and the development of effective preventions and interventions can reduce its prevalence and the severe impacts on a patient's quality of life, as well as psychosocial functioning [9].

ADHD can stem from biological and psychosocial causes and can be influenced by personal, familial, and social factors similar to other psychiatric disorders $[10,11]$. Genetic predispositions [12], male gender, younger age [13], birth weight (BW) [14], stronger aggressive behavior, and increasing symptoms of 
generalized anxiety [13] are related with ADHD symptoms. Also, there is some evidence that the familial factors like unplanned pregnancies, psychosocial stress of the mother during pregnancy [12], preterm delivery $[15,16]$, delivery mode, shared decision-making regarding medical procedures during the delivery, perinatal bonding, quality of parent-child relationship [12], and parent's mental health status [17] can play important roles in onset and development of ADHD.

Furthermore, some social risk factors like social support, parent's migration, and socioeconomic status (SES) are related to ADHD or moderate the relationship between ADHD and its associated factors. It was shown that children in families of low SES are more likely to have ADHD than their peers in high SES families. In spite of substantial between-study heterogeneity, there is an evidence for the association between socioeconomic disadvantage and risk of ADHD [17]. Not only is there a direct relationship between ADHD and SES, but it can also influence its occurrence via factors linked to low SES such as parental mental health and maternal smoking during pregnancy [17]. This study is aimed to evaluate the associated risk factors with ADHD.

\section{Methods}

This case-control study recruited 297 children with a diagnosis of ADHD (cases) and 297 controls (non-ADHD children) matched 1:1.

\section{Study sample}

The patients were chosen from cases who were diagnosed with ADHD when they referred to Tehran Institute of Psychiatry (School of Behavioral Sciences and Mental Health), Tehran, Iran, 2012-2013. Children aged 5-12 years who had no major sensorimotor disabilities were included in the study. Children with an unclear family background and adopted children were excluded. Controls were selected from outpatient services of general pediatric medical centers. The study group and controls were matched in terms of their age interval ( \pm 1 year).

A child psychiatrist diagnosed ADHD and confirmed it using ADHD Rating Scale-IV (ADHD-RS-IV) - Home Version [18] which has been validated in Iran [19], and the parents were asked to complete the scale. This scale was chosen because of its appropriate psychometric characteristics, technical adequacy, and a small number of the questions [20]. Non-ADHD participants were also assessed physiologically and psychiatrically and their mothers were also asked to complete the ADHD Rating Scale-IV [18]. The children's birth weight, gender, delivery date [preterm (before $37^{\text {th }}$ week), term, post-term (after $42^{\text {nd }}$ week) [21], delivery type [caesarean section (CS) and normal vaginal delivery (NVD)], offspring, childhood events (parents' divorce, death of one of the family members, car accident, parent's addiction), maternal diseases during pregnancy (diabetes, psychological disease, chronic liver or kidney disease, immune system diseases, congenital heart disease, seizure disorder or convulsion), neonatal diseases (hypoglycemia, severe hyperbilirubinemia, chronic kidney and liver disease, immunodeficiency disease), and mother's level of education being included in the study, were assessed by an interview with mothers. The children were categorized into three groups based on BW as low $(<2500 \mathrm{~g})$, normal BW (2500-3500 g), and high BW ( $>3500 \mathrm{~g})$. Based on WHO birth weight chart, $\mathrm{BW}>3500 \mathrm{~g}$ which is $75^{\text {th }}$ percentile for BW was considered as high BW. The patients' mothers signed a written informed consent for participation of their children. This study was approved by the Ethics Committee of Iran University of Medical Sciences.

\section{Statistical analysis}

Qualitative variables were reported using mean \pm standard deviation (SD) and qualitative variables were described by frequency (\%). Chi-square and t-test were used to compare the qualitative and quantitative variables between groups, respectively. Conditional binary logistic regression was used to assess the risk factors of ADHD for the matched pairs. Hosmer-Lemeshow method was used for variable selection [22]. Factors with a p-value less than 0.2 in the univariate model were included in the multiple models. Variables with a p-value less than 0.05 were retained in the final model. The results were expressed with odds ratio (OR) and $95 \%$ confidence interval $(95 \% \mathrm{CI})$. HosmerLemeshow test was considered for model goodness-of-fit. Statistical analysis was performed using R 3.4.3. The level of significance was considered $<0.05$.

\section{Ethical approval}

All procedures performed in studies involving human participants were in accordance with the ethical standards of the institutional and/or national research committee and with the 1964 Helsinki declaration and its later amendments or comparable ethical standards. The study was approved by Ethics Committee of Iran University of Medical Sciences.

\section{Results}

In total, 297 ADHD and 297 non-ADHD children completed the study. There were $224(75.5 \%)$ and 215 $(72.4 \%)$ males in the case and control groups, respectively. The mean $\pm \mathrm{SD}$ age was $8.8 \pm 3.14$ years in the case group and $8.11 \pm 2.9$ years in the control group $(\mathrm{P}=0.61$, Table I). Table I shows that children's mean \pm SD BW was higher in the ADHD group compared with the controls $(3245.09 \pm 0.66 \mathrm{~g}$ vs. $3026.56 \pm 0.45 \mathrm{~g}, \mathrm{P}=0.04)$. Demographic characteristics of the mothers and children were significantly different between the case and control groups $(\mathrm{P}<0.001$, Table I). Table I shows that $244(83 \%)$ of the non-ADHDs had a normal BW and 73 (34\%) of the ADHDs had a high BW. The children with the neonatal disease, children whose mothers had a disease, and children who were delivered by Cesarean Section (CS) had a higher percentage of ADHD. Table II shows the number of cases and controls in terms of BW and gender in the ADHD and non-ADHD groups. Seventy-nine (35.5\%) and $22(10 \%)$ of the infants were male and had a low BW in the ADHD and non-ADHD groups, respectively. In total, $8 \%$ of the male and $9.5 \%$ of the female had low BW (results not shown). Univariate analysis showed that the higher risk of ADHD 
was significantly related to BW, experience of neonatal disease, CS delivery, fewer offspring, lower level of mothers' education, and preterm delivery (Table III, $\mathrm{P}<0.05$ ).

Regarding multiple regression, higher $\mathrm{BW}$, experience of neonatal disease, fewer offspring, lower mothers' education level, and preterm delivery were also risk factors for the higher odds of ADHD. The odds of ADHD in the children with high BW were 3.36 (1.96-5.78) times the odds of ADHD in the normal BW children adjusted for the other risk factors. However, the odds of ADHD in the low and normal BW children were not statistically different $[1.74$ (0.7-3.7)]. Furthermore, the odds of ADHD in the preterm infant were 8.68 (2.55-28.5) times the odds of ADHD in the term infants. The children who experienced neonatal disease had a higher risk of ADHD compared with the children who had none [2.93 (1.55-5.54)]. It was demonstrated that CS delivery was not associated with ADHD risk [1.6 (0.97, 2.64)]. Moreover, no co-linearity was observed between the delivery date and $\mathrm{BW}(\mathrm{r}=0.29, \mathrm{P}=0.07)$. Hosmer-Lemeshow statistics showed a decent fit.

Table I. Frequency (\%) and mean \pm SD of mother and children demographic characteristics.

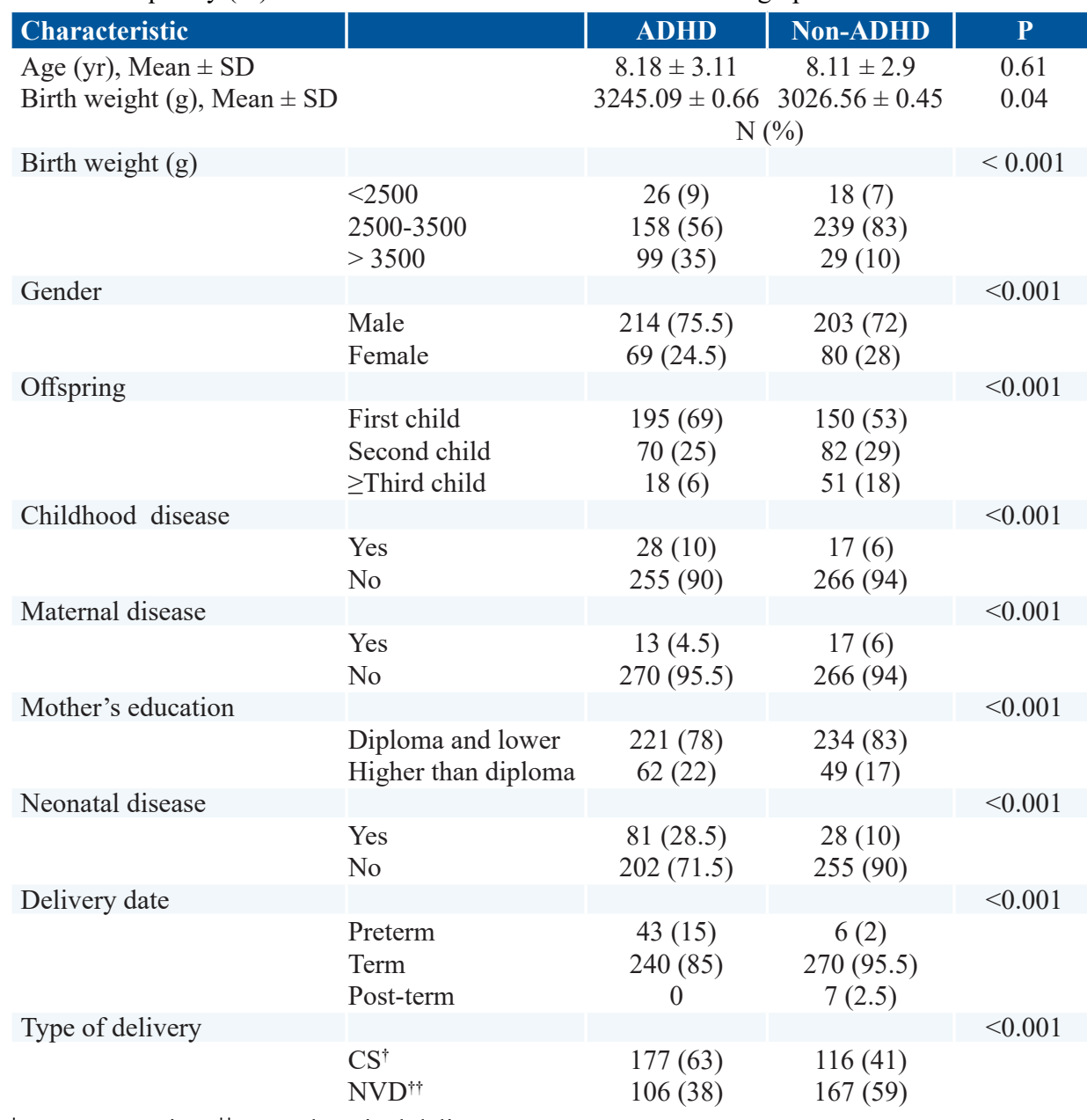

${ }^{\dagger}$ Cesarean section, ${ }^{\dagger}$ Normal vaginal delivery

Table II. Frequency (\%) of ADHD and Non-ADHD in low, normal, and high BW in male and female children.

\begin{tabular}{lcc|c|c} 
& \multicolumn{2}{|c|}{ ADHD } & \multicolumn{2}{c}{ Non-ADHD } \\
\hline Birth weight & Male & Female & Male & Female \\
\hline Low & $17(7.5)$ & $9(12.5)$ & $18(8.5)$ & $6(7.5)$ \\
Normal & $128(57)$ & $42(57.5)$ & $175(81.5)$ & $69(84)$ \\
High & $79(35.5)$ & $22(30)$ & $22(10)$ & $7(8.5)$ \\
Total & 224 & 73 & 215 & 82
\end{tabular}


Table III. Frequency (\%) of factors in ADHD patients using univariate and multiple analysis.

\begin{tabular}{|c|c|c|c|}
\hline \multirow{2}{*}{ Factor } & \multirow{2}{*}{$\%$ ADHD } & \multicolumn{2}{|c|}{ OR $(95 \% C I)$} \\
\hline & & Univariate analysis & Multiple analysis \\
\hline \multicolumn{4}{|l|}{ Birth weight (gr) } \\
\hline Normal (2500-3500) & $170 / 408(41.6 \%)$ & - & - \\
\hline Low $(<2500)$ & $36 / 46(77.7 \%)$ & $3.82(2.46,5.91)^{*}$ & $3.36(1.96,5.78)^{*}$ \\
\hline $\operatorname{High}(>3500)$ & $73 / 130(56 \%)$ & $1.6(0.83,3.04)$ & $1.74(0.7,3.7)$ \\
\hline Gender (female/male) & $47 \%$ vs $51 \%$ & $0.85(0.58,1.23)$ & - \\
\hline Childhood disease (yes/no) & $59 \%$ vs $49 \%$ & $1.45(0.82,2.56)$ & - \\
\hline Maternal disease (yes/no) & $51 \%$ vs $50 \%$ & $1.06(0.52,2.15)$ & - \\
\hline Neonatal disease (yes/no) & $71 \%$ vs $45 \%$ & $3.17(1.98,5.07)^{*}$ & $2.93(1.55,5.54)^{*}$ \\
\hline Delivery type $\left(\mathrm{CS}^{\dagger} / \mathrm{NVD}^{\dagger \dagger}\right)$ & $59 \%$ vs $40 \%$ & $2.48(1.69,3.64)^{*}$ & - \\
\hline \multicolumn{4}{|l|}{ Offspring } \\
\hline First & $200 / 356(56 \%)$ & - & - \\
\hline Second & $72 / 151(47.7 \%)$ & $0.73(0.5,1.06)$ & $0.58(0.35,0.96)^{*}$ \\
\hline$\geq$ Third & $25 / 83(30 \%)$ & $0.38(0.23,0.62)^{*}$ & $0.34(0.17,0.66)^{*}$ \\
\hline \multicolumn{4}{|l|}{ Mother's education } \\
\hline Less than diploma & $83 / 122(68 \%)$ & - & - \\
\hline Diploma & $149 / 356(41.8 \%)$ & $0.32(0.2,0.52)^{*}$ & $0.24(0.12,0.47)^{*}$ \\
\hline Higher than diploma & $65 / 116(56 \%)$ & $0.58(0.33,1.01)$ & $0.43(0.21,0.9)^{*}$ \\
\hline \multicolumn{4}{|l|}{ Delivery date } \\
\hline Term & $246 / 468(46 \%)$ & - & - \\
\hline Preterm & $43 / 50(86 \%)$ & $8.2(3.22,20.87)^{*}$ & $8.68(2.55,28.5)^{*}$ \\
\hline Post-term & $8 / 16(50 \%)$ & $1.4(0.48,3.96)$ & $1.00(0.2,4.81)$ \\
\hline
\end{tabular}

${ }^{\dagger}$ Cesarean section, ${ }^{\dagger}$ Normal vaginal delivery, "significant at the level of 0.05

\section{Discussion}

The present study aimed to investigate the potential ADHD risk factors. We have found that preterm delivery is related to increased ADHD risk, similar to previous studies [13,16,23-25]. Furthermore, pre- and post-term delivery was associated with a higher ADHD risk. Based on the data, another risk factor for ADHD was the occurrence of at least one of the neonatal diseases such as hypoglycemia, severe hyperbilirubinemia, important chronic kidney disease, important chronic liver disease, and immunodeficiency disease. This finding may implicate that we can prevent the incidence of ADHD by preventing and treating these neonatal diseases. Also, our results showed that the higher level of mother education and higher offspring had a protective effect on the ADHD incidence, which is consistent with Russel et al findings [17]. We found a significant association between $\mathrm{BW}$ and ADHD risk, which is confirmed by original studies $[12,13,16,26]$ in addition to a meta-analysis [23]; they reported that lower BW was related to the higher risk of ADHD, while we found that the high BW children had a higher ADHD risk compared with the normal BW children adjusted for the other factors. Indeed, the different results could be due to different BW categorization, study population, and study design.

Moreover, in contrast with previous studies $[25,27,28]$, the current study indicated that there was no significant association between ADHD and maternal diseases in the studied sample. No significant association was found between gender and ADHD in our study; however, ADHD was reported to be more common in males than females according to a systematic review by Shooshtari et al in Iran [8]. In the present study, delivery type was not detected as a risk factor for ADHD, which is consistent with recent reports [29,30], although this result was in contrast to Talge et al that demonstrated that term children - born by CS delivery and preceded by induced labor - experienced more ADHD symptoms [31].

The prevalence of low BW $(<2500 \mathrm{~g})$ in the male $(8 \%)$ and female $(9.5 \%)$ children was similar to Rafiei's finding [32]. In addition, in our results the proportion of the low BW children was similar in the ADHDs and nonADHDs.

The strength point of this study can be the patients who are representative of the population of Tehran, capital of Iran, because Tehran Institute of Psychiatry is a highvolume referral center in Tehran.

Maternal recall bias, in term of recalling the past diseases and events of their children (recall bias), is one of the limitations in case-control studies. Another limitation of this study was that SES was not measured directly. However, the level of maternal education, offspring, BW, and delivery date could be indicators of family SES $[27,28]$. In order to do further exploration, ethnicity, maternal smoking status, and Apgar score should be considered in prospective studies, which may be helpful in better understanding and detecting the ADHD risk factors. 


\section{Conclusion}

Based on this study, children who had preterm birth, higher BW, and at least one of the neonatal diseases such as hypoglycemia, severe hyperbilirubinemia, serious chronic kidney disease, serious chronic liver disease and immunodeficiency diseases had higher risk of ADHD, suggesting that the individual and social harmful effects of this disorder can be prevented by controlling the associated factors before or immediately after birth.

Moreover, the higher level of mother education and having more offspring can be considered as protective factors for ADHD. In summary, future studies could clear the controversies incorporating more clinical factors at birth, utilizing more precise methodologies in large samples.

\section{Acknowledgement}

The authors wish to thank mothers who participated in the study. We would also like to show our gratitude to the Rasoul Akram Hospital Research Development Center (RCRDC) for its editorial assists.

\section{References}

1. American Psychiatric Association. Diagnostic and Statistical Manual of Mental Disorders. $5^{\text {th }}$ ed. Washington, DC: American Psychiatric Press; 2013: pp. 31-35.

2. Sadock BJ, Sadock VA. Kaplan \& Sadock's Comprehensive Textbook of Psychiatry. Philadelphia: Lippincott Williams \& Wilkins; 2000: pp. 3560-3571.

3. Oyebode F. Sims' Symptoms in the Mind: Textbook of Descriptive Psychopathology. $6^{\text {th }}$ ed. Edinburgh: Saunders/ Elsevier; 2015: pp. 45-58.

4. Sadock BJ, Sadock VA, Ruiz P. Kaplan \& Sadock’s Synopsis of Psychiatry: Behavioral Sciences/clinical Psychiatry. $7^{\text {th }}$ ed. Philadelphia: Wolters Kluwer; 2015: pp. 4177-4202.

5. de Graaf-Peters VB, Hadders-Algra M. Ontogeny of the human central nervous system: what is happening when? Early Hum Dev. 2006;82:257-266.

6. Faraone SV, Sergeant J, Gillberg C, Biederman J. The worldwide prevalence of ADHD: is it an American condition? World Psychiatry. 2003;2:104-113.

7. Polanczyk GV, Willcutt EG, Salum GA, Kieling C, Rohde LA. ADHD prevalence estimates across three decades: an updated systematic review and meta-regression analysis. Int J Epidemiol. 2014;43:434-442.

8. Shooshtary MH, Chimeh N, Najafi M, Mohamadi MR, Yousefi-Nouraie R, Rahimi-Mvaghar A. The prevalence of attention deficit hyperactivity disorder in Iran: A systematic review. Iran J Psychiatry. 2010;5:88-92.

9. Van Lieshout RJ, Boyle MH. Is bigger better? Macrosomia and psychopathology later in life. Obes Rev. 2011;12:e405-e411.

10. Masten AS, Cutuli JJ, Herbers JE, Reed M-G. Resilience in development. In: Snyder CR, Lopez J, editors. Oxford handbook of positive psychology. New York: Oxford
University Press; 2009: pp. 117-132.

11. Wille N, Bettge S, Ravens-Sieberer U; BELLA Study Group. Risk and protective factors for children's and adolescents' mental health: results of the BELLA study. Eur Child Adolesc Psychiatry. 2008;17 Suppl 1:133-147.

12. Tole F, Kopf J, Schröter K, Palladino VS, Jacob CP, Reif $\mathrm{A}$, et al. The role of pre-, peri-, and postnatal risk factors in bipolar disorder and adult ADHD. J Neural Transm (Vienna). 2019;126:1117-1126.

13. Wüstner A, Otto C, Schlack R, Hölling H, Klasen F, RavensSieberer U. Risk and protective factors for the development of ADHD symptoms in children and adolescents: Results of the longitudinal BELLA study. PLoS One. 2019;14:e0214412.

14. Strang-Karlsson S, Räikkönen K, Pesonen AK, Kajantie E, Paavonen EJ, Lahti J, et al. Very low birth weight and behavioral symptoms of attention deficit hyperactivity disorder in young adulthood: the Helsinki study of very-lowbirth-weight adults. Am J Psychiatry. 2008;165:1345-1353.

15. Guyer B, Hoyert DL, Martin JA, Ventura SJ, MacDorman MF, Strobino DM. Annual summary of vital statistics - 1998. Pediatrics. 1999;104:1229-1246.

16. Anderson PJ, De Luca CR, Hutchinson E, Spencer-Smith MM, Roberts G, Doyle LW, et al. Attention problems in a representative sample of extremely preterm/extremely low birth weight children. Dev Neuropsychol. 2011;36:57-73.

17. Russel AE, Ford T, Williams R, Russell G. The Association between Socioeconomic Disadvantage and Attention Deficit/ Hyperactivity Disorder (ADHD): A Systematic Review. Child Psychiatry Hum Dev. 2016;47:440-458.

18. Dupaul GJ, Power TJ, Anastopoulos AD, Reid R. ADHD Rating Scale IV Checklists, Norms, and Clinical Interpretation. New York: Guilford Press; 1998: pp. 172-178.

19. Ghanizadeh A, Jafari P. Cultural structures of the Persian parents' ratings of ADHD. J Atten Disord. 2010;13:369-373.

20. Pappas D. ADHD Rating Scale-IV: Checklists, norms, and clinical interpretation. J Psychoeduc Assess. 2006;24:172-178.

21. International statistical classification of diseases and related health problems: World Health Organization; 2004. Available from: https://apps.who.int/iris/handle/10665/42980.

22. Jewell NP. Statistics for epidemiology. Boca Raton, FL: Chapman and Hall/CRC; 2003, Chapter 15: pp. 255-269.

23. Franz AP, Bolat GU, Bolat H, Matijasevich A, Santos IS, Silveira RC, et al. Attention Deficit/Hyperactivity Disorder and Very Preterm/Very Low Birth Weight: A Meta-analysis. Pediatrics. 2018;141:e20171645.

24. Heinonen K, Räikkönen K, Pesonen AK, Andersson S, Kajantie E, Eriksson JG, et al. Behavioural symptoms of attention deficit/hyperactivity disorder in preterm and term children born small and appropriate for gestational age: a longitudinal study. BMC Pediatr. 2010;10:91.

25. El Marroun H, Zeegers M, Steegers EA, van der Ende J, Schenk JJ, Hofman A, et al. Post-term birth and the risk of behavioral and emotional problems in early childhood. Int $\mathrm{J}$ Epidemiol. 2012;41:773-781.

26. Hanć T, Szwed A, Słopień A, Wolańczyk T, DmitrzakWęglarz M, Ratajczak J. Perinatal risk factors and ADHD in 
children and adolescents: a hierarchical structure of disorder predictors. J Atten Disord. 2018;22:855-863.

27. Kosińska M. Perinatal outcome of offspring as the effects of interactions of the fetus motherenvironment system factors: Wydawnictwo Naukowe Uniwersytetu im. Adama Mickiewicza; 2011: pp. 58-61.

28. Verropoulou G, Basten S. Very low, low and heavy weight births in Hong Kong SAR: how important is socioeconomic and migrant status? J Biosoc Sci. 2014;46:316-331.

29. Curran EA, O’Neill SM, Cryan JF, Kenny LC, Dinan TG, Khashan AS, et al. Research review: Birth by caesarean section and development of autism spectrum disorder and attention- deficit/hyperactivity disorder: a systematic review and metaanalysis. J Child Psychol Psychiatry. 2015;56:500-508.

30. Curran EA, Cryan JF, Kenny LC, Dinan TG, Kearney PM, Khashan AS. Obstetrical mode of delivery and childhood behavior and psychological development in a British cohort. J Autism Dev Disord. 2016; 46:603-614.

31. Talge NM, Allswede DM, Holzman C. Gestational age at term, delivery circumstance, and their association with childhood attention deficit hyperactivity disorder symptoms. Paediatr Perinat Epidemiol. 2016;30:171-180.

32. Rafiei M. Prevalence of low birth weight and obesity in newborn in Arak. Iran J Pediatr. 2007; 17:47-53. 